\title{
Effect of Recycled Concrete Waste Aggregate on the Fresh State Properties of Self Compacting Concrete

\author{
Shijumon.V, Nalanth.N
}

\begin{abstract}
In this investigation an attempt is made to replace coarse aggregate partially or fully by recycled concrete waste aggregates and the fresh state properties of modified SCC (Self Compacting Concrete) was elaborated by conducting slump flow, $V$-funnel, L-Box and J-ring tests. The properties such as filling ability, passing ability, segregation, bleeding and stability of the modified SCC were determined by using the fresh state tests. The results of this experiment revealed that it is possible to modify SCC by partially or fully replacing the coarse aggregate by RCWA. The optimum mix also determined by varying RCWA and mineral admixture content in SCC.
\end{abstract}

Keywords: Self Compacting Concrete, Recycled Concrete Waste Aggregate, Fresh state properties, segregation, passing ability.

\section{INTRODUCTION}

Self compacting concrete (SCC) was first introduced in Japan. Mainly SCC mix is used in complex structural applications. Concrete materials are taken from the natural resources which causes environmental degradation and pollution. In recent years SCC is widely used in various applications because of its high workability. Normally contribution of aggregates in SCC mix is about $60 \%$. So it plays an important role in fresh properties of SCC mix. Based on the aggregate shape, size and texture values of fresh state properties values get varied. Various alternative materials have been identified to replace the aggregates partially or fully. The size and shape of the coarse aggregate has an impact on amount of necessary to bind all the particles [1]. Flow ability of the SCC mix was reduced by the interlocking of the angular particles of crushed aggregates at the same time flow ability increased with rounded aggregates [2]. To achieve a successful and economical SCC, it is necessary to use properly graded aggregates. Production of SCC mix may also be possible with the poorly graded aggregate but providing adequate viscosity to eradicate segregation problem. Passing ability of the mix depends on the size of the coarse aggregate an increase in size of aggregate reduces the passing ability of the concrete. The optimum size of coarse aggregate is selected by two parameters such as size and shape. Maximum size of aggregate size in SCC mix is about $10-12 \mathrm{~mm}$ [3].This investigation is aimed at attaining an optimum content of RCWA which yields desired SCC fresh state properties.

Revised Manuscript Received on October 30, 2019.

* Correspondence Author

Shijumon.V*, Research Scholar.at Noorul Islam Centre for Higher, Kumaracoil, Kanyakumari District, Tamilnadu, INDIA.

Nalanth.N, Professor in the Department of Civil Engineering at Noorul Islam Centre for Higher, Kumaracoil, Kanyakumari District, Tamilnadu, INDIA.

(c) The Authors. Published by Blue Eyes Intelligence Engineering and Sciences Publication (BEIESP). This is an open access article under the CC BY-NC-ND license (http://creativecommons.org/licenses/by-nc-nd/4.0/)
Mixes were prepared in various percentages (30\%, 40\% and $50 \%$ ) of RCWA. In addition to this Steel fibre in suitable proportion of the order of $0.5,0.75$ and $1 \%$ was added to the SCC mixes and the fresh state properties were determined.

\section{EXPERIMENTAL PROGRAM}

\section{A. Work Materials}

Ordinary Portland cement of grade 43 was used in this experimental investigation. Fly ash is the mineral admixture used as a partial replacement to cement in order to enhance the workability properties of the concrete. Fly ash is derived from thermal power plant situated in Neyveli district. Addition of fly ash in SCC mix also regulates the level of viscosity [4]. Fly ash also provides resistance to sulphate attack and hinders the alkali aggregate reaction. Recycled concrete waste aggregate taken from nearby demolished buildings and of size about $10 \mathrm{~mm}-12 \mathrm{~mm}$ was used in the investigation. Addition of RCWA percentages was varied from $30 \%$ to $50 \%$. Water absorption ratio of the concrete mix was observed to be about 0.5 . Poly carboxylate based super plasticizer was used as a water reducing agent in this investigation.

\section{B. Mix proportions}

Mix proportioning was made as per the guidelines given in EFNARC. Water to binder ratio value is fixed about 0.5 and the water content of $208 \mathrm{lit} / \mathrm{m} 3$ was determined and the cement content is $291.2 \mathrm{~kg} / \mathrm{m} 3$. Cement was partially replaced by fly ash and the volume of fly ash is fixed about $124.8 \mathrm{~kg} / \mathrm{m} 3$. RCWA content is varied from $30 \%$ to $50 \%$. While preparing the SCC mixes the stability of the mixtures were determined using visual stability index. To achieve the required stability the contents of the SCC mixture were varied. The $\mathrm{SP}$ content was about $7.23 \mathrm{lit} / \mathrm{m} 3$ to achieve the slump flow values of $700 \pm 40 \mathrm{~mm}$ [5]. Normal SCC mix is taken for the reference mix (M0). M1 is prepared by replacing $30 \%$ of RCWA in the place of natural aggregates. Similarly M2 and M3 were prepared by replacing natural aggregates by $40 \%$ and $50 \%$ respectively. M4, M5 and M6 were prepared by replacing RCWA in the place of natural aggregates and the steel fibre addition is in the order od 0.5, 0.75 and $1 \%$ respectively. Mix proportions are tabulated in Table I..

\section{A. Procedures for testing}

The fresh state properties are tested based on the guidelines given in EFNARC (2005) [6]. The values of slump flow diameter, T500 flow time, L-box height ratio, $\mathrm{V}$ funnel flow time values are fixed according to EFNARC guidelines. Figure 1 represents the rough draft of slump flow testing equipment. 
Normally slump flow value $650 \mathrm{~mm}$ is the optimum value ability. of SCC mix and the flow time decreases with increase in flow

Table I Mix proportioning of SCC

\begin{tabular}{|c|c|c|c|c|c|c|c|c|c|c|c|}
\hline $\begin{array}{l}\text { Sl. } \\
\text { No. }\end{array}$ & Mix ID & \begin{tabular}{|l} 
Steel \\
Fibers \\
$\%$
\end{tabular} & $\begin{array}{l}\text { Cemen } \\
\text { t } \\
\left(\mathrm{kg} / \mathrm{m}^{3}\right. \\
\end{array}$ & $\begin{array}{l}\text { Fly } \\
\text { ash } \\
\left(\mathrm{kg} / \mathrm{m}^{3}\right.\end{array}$ & $\begin{array}{l}\text { Wate } \\
r^{2}\left(1 / \mathrm{m}^{3}\right.\end{array}$ & 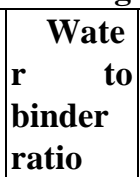 & $\begin{array}{l}\text { FA } \\
\left(\mathrm{kg} / \mathrm{m}^{3}\right.\end{array}$ & $\begin{array}{l}\text { CA } \\
\text { (Kg/m }\end{array}$ & $\mathrm{A}^{2} \begin{array}{l}\text { RCW } \\
\text { (Kg/m }\end{array}$ & $\begin{array}{l}\text { SP } \\
\% \\
\text { CM }\end{array}$ & $\begin{array}{l}\text { SP } \\
\left(\mathbf{L} / \mathbf{m}^{3}\right. \\
\end{array}$ \\
\hline 1 & M0 & - & 291.2 & 124.8 & 208 & 0.5 & 989.84 & 809.87 & - & 1.68 & 7.0 \\
\hline 2 & M1 & - & 291.2 & 124.8 & 208 & 0.5 & 989.84 & $\begin{array}{l}566.9 \\
\end{array}$ & 242.9 & 2.16 & 9.5 \\
\hline 3 & M2 & - & 291.2 & 124.8 & 208 & 0.5 & 989.84 & 485.93 & 323.94 & 2.58 & 10.75 \\
\hline 4 & M3 & - & 291.2 & 124.8 & 208 & 0.5 & 989.84 & 404.93 & 404.93 & 2.95 & 12.28 \\
\hline 5 & M4 & 0.5 & 291.2 & 124.8 & 208 & 0.5 & 989.84 & 566.9 & 242.9 & 2.35 & 9.8 \\
\hline 6 & M5 & 0.75 & 291.2 & 124.8 & 208 & 0.5 & 989.84 & 485.93 & 323.94 & 2.64 & 10.98 \\
\hline 7 & M6 & 1.0 & 291.2 & 124.8 & 208 & 0.5 & 989.84 & 404.93 & 404.93 & 3.04 & 12.67 \\
\hline
\end{tabular}

Flow ability of the SCC mix values were determined by the slump flow and flow time.

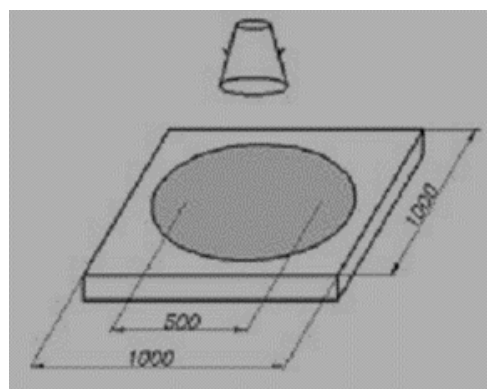

Figure 1 Slump cone apparatus, EFNARC (2005)

By using the apparatus represented in figure 1 was used to inspect the consistence of fresh concrete. T500 time was used to determine the concrete segregation resistance and uniformity of the SCC mix. SCC mix takes to flow $500 \mathrm{~mm}$ diameter was mentioned using flow time.

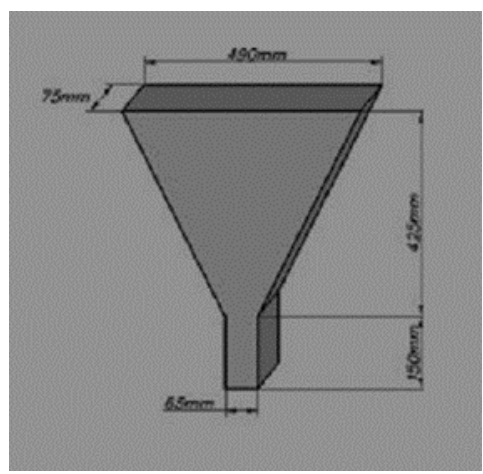

Figure 2 V-Funnel Apparatus EFNARC (2005)

Computation of T50 slump flow time and V-funnel time was used to determine the viscosity value of SCC. V-shaped funnel apparatus was utilized to determine the value of V-funnel flow time. Funnel is filled with the SCC mix and then it is allowed to flow out. The time period required to empty the V-funnel apparatus was noted as V-funnel time. The passing ability of SCC mix was determined by using J-ring test. Test apparatus setup is shown in figure 3. J-ring was situated around the slump cone. The difference in slump flow is observed as passing ability [8].

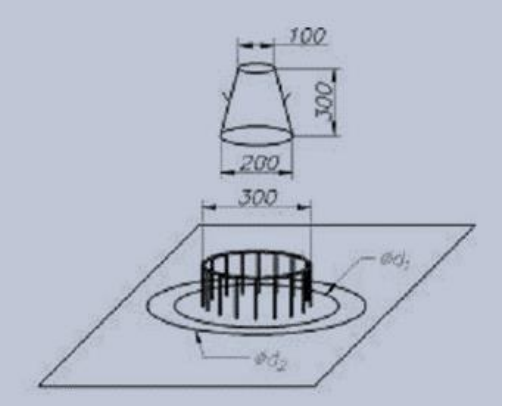

Figure 3 J-Ring Apparatus EFNARC (2005)

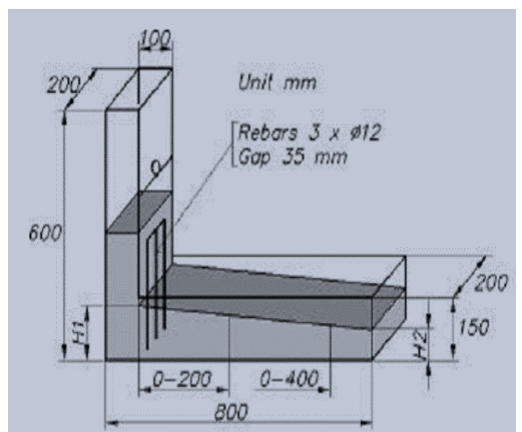

Figure 4 L-Box Test Apparatus EFNARC (2005)

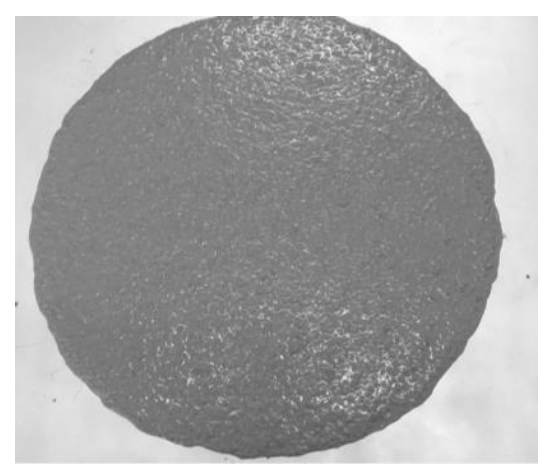

Figure 5 Slump flow measurement of SCC 


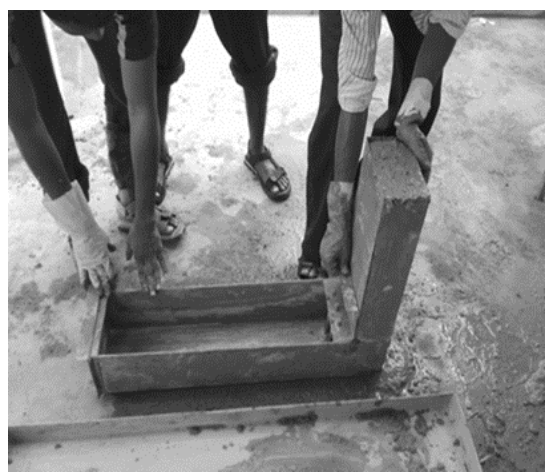

Figure 6 L-box test on SCC

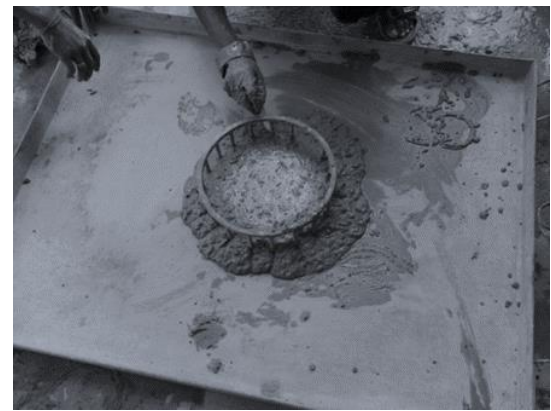

Figure 7 J-ring test on SCC trial mix

This test also explains the horizontal movement of fresh SCC mix through the vertical reinforcing rods. The height of the concrete at both the ends of the horizontal section was measured and expressed as $\mathrm{H}_{2} / \mathrm{H}_{1}$. Slump flow, L- Box and J-ring tests were performed and the results are tabulated in table II

Table II Fresh state properties of SCC

\begin{tabular}{|c|c|c|c|c|c|}
\hline \multirow{2}{*}{$\begin{array}{c}\text { MIX } \\
\text { ID }\end{array}$} & \multicolumn{5}{|c|}{ Fresh state test } \\
\cline { 2 - 6 } & $\begin{array}{c}\text { Slump flow } \\
\text { D }\end{array}$ & $\begin{array}{c}\mathbf{T}_{\text {500 }} \\
\text { (Sec) }\end{array}$ & $\begin{array}{c}\text { J-ring } \\
\text { (mm) }\end{array}$ & $\begin{array}{c}\text { L-Box } \\
\text { (mm) }\end{array}$ & $\begin{array}{c}\text { V- } \\
\text { Funnel } \\
\text { (Sec) }\end{array}$ \\
\hline M0 & 740 & 2 & 7.3 & 1.0 & 8.31 \\
\hline M1 & 735 & 2.37 & 7.6 & 0.97 & 8.94 \\
\hline M2 & 723 & 2.98 & 7.7 & 0.89 & 9.17 \\
\hline M3 & 718 & 3.25 & 8.5 & 0.87 & 9.52 \\
\hline M4 & 723 & 3.65 & 8.9 & 0.85 & 10.25 \\
\hline M5 & 717 & 3.97 & 9.5 & 0.83 & 10.88 \\
\hline M6 & 707 & 4.29 & 9.9 & 0.82 & 11.08 \\
\hline
\end{tabular}

\section{RESULTS AND DISCUSSION}

\section{A.Fresh properties}

The stability and filling ability of SCC mixes were determined by the factors such as passing capacity, flow ability, viscosity and segregation resistance. Each of these factors were evaluated by single or multiple testing procedures given in EFNARC. Flow capacity of SCC mix was assessed by slump flow test. Viscosity of SCC mix was attained by conducting T500 slump flow time and V-funnel time tests. The values of all the tests were recorded and graphically represented in figure 8 .

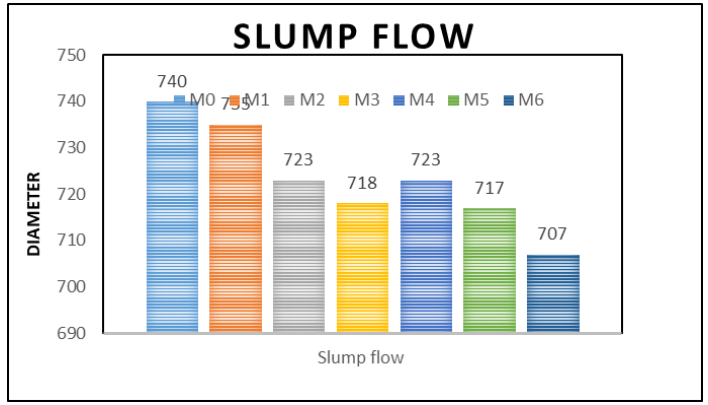

Figure 8 Slump flow values of SCC mix

From the results it is evident that the replacement of natural aggregates by RCWA reduced the slump flow values of SCC mix. Increasing the RCWA content more than $50 \%$ caused an unacceptable flow. This is due to the high angularity of RCWA content in SCC mix and it reduced the workability of the concrete mix.

\section{B. T500 measurements}

T500 times of SCC mixes are shown in figure 9. As seen in figure T500 time is gradually increase with increase in RCWA content in SCC and more than 50\% of RCWA.. The mobility values are decreased with increase in RCWA content.

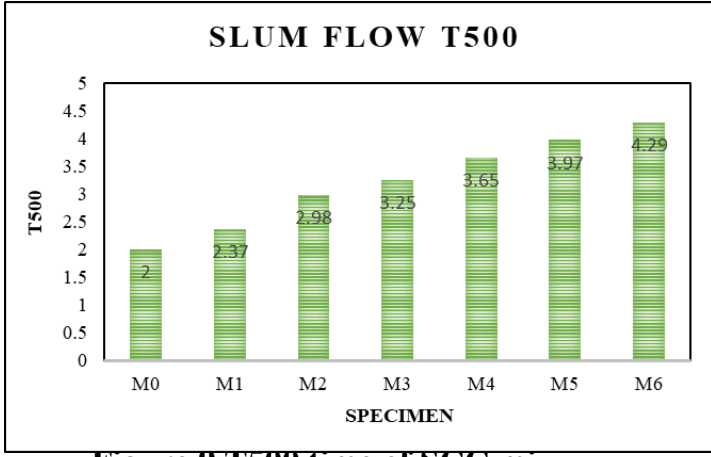

Figure 9 T500 time of SCC mix

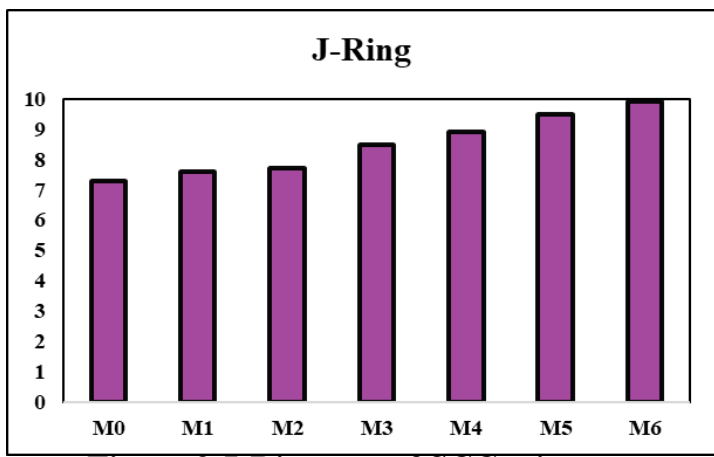

Figure 9 J-Ring test of SCC mix

\section{L-Box tests}

The blocking ability of SCC mixes are determined by using L-Box apparatus. The values are graphically represented in figure 10 . As seen in figure the ratio of $\mathrm{H} 2 / \mathrm{H} 1$ reduced with increase in RCWA content. Higher replacement levels of RCWA exhibits the negative behaviour of SCC mix. So the optimum values of viscosity is attained at $30 \%$ of replacement levels.

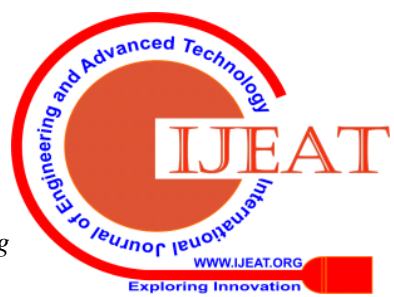




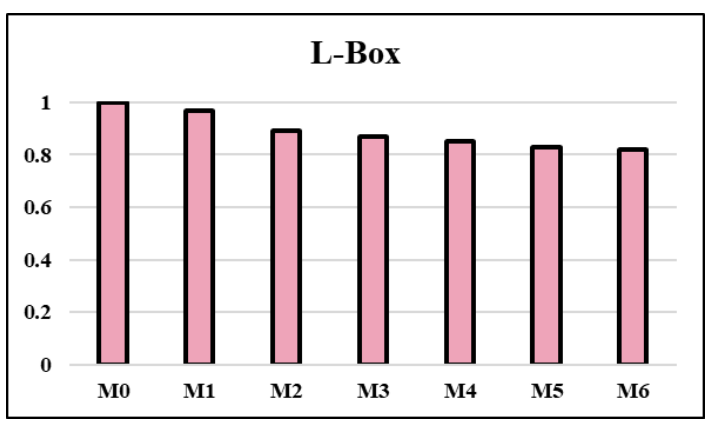

Figure 9 L-Box test of SCC mix

\section{B. V-Funnel Time}

V-funnel time of the SCC mixtures exhibited similar tendency to that of T500 slump flow time. From the figure it is revealed that the increase in replacement levels of RCWA elevated the V-Funnel times.

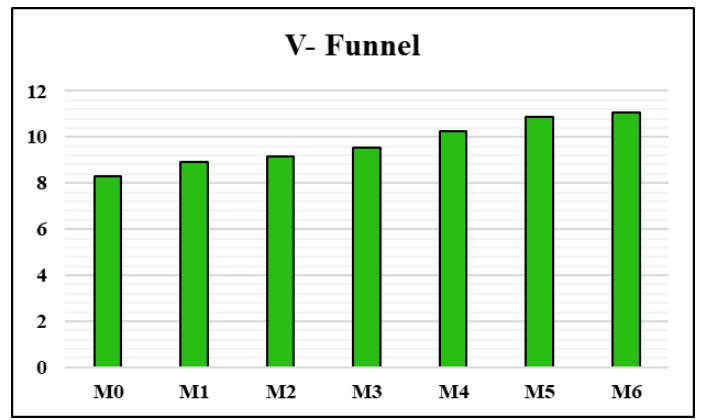

Figure $10 \mathrm{~V}$-Funnel test of SCC mix

\section{CONCLUSION}

This investigation has suggested an alternate coarse aggregate for the preparation of Self Compacting Concrete mix. The flow ability of SCC decreases with increase in RCWA content. The addition of fly ash as a partial replacement of cement reduced the flow ability of SCC mix and increased the viscosity which enhanced the strength properties of modified SCC. From this investigation it is inferred that the usage of RCWA in SCC mix satisfactorily meet the requirements of SCC mix.

\section{REFERENCES}

1. Neuwald, A (2004). " Self-Consolidating Concrete" MC Magazine, pp. $2-4$

2. Alexander, C. and Prosk (2003), T.," Self-Compacting Concrete-Influence of the Coarse Aggregate on The fresh Concrete Properties" http://www.darmstadt-concrete.de ,, pp. 1

3. Petersson, O. (1997), "Preliminary Mix Design"Final Report of Task 1, Sweedish Cement and Concrete Research Institute, pp.15-19.

4. A. Bilodeau, V. Sivasundaram, K.E. Painter, V.M. Malhotra, Durability of concrete incorporating high volume of fly ash from source in US, ACI Mater.J. 91 (1) (1994) 3-13.

5. K.-H. Yang, Y.-B. Jung, M.-S. Cho, S.-H. Tae, Effect of supplementary cementitious materials on reduction of CO2 emissions from concrete, J.Clean. Prod. 103 (2015) 774-783, https://doi.org/10.1016/j.jclepro.2014.03.018.

6. EFNARC (2005) Specification and guidelines for self-compacting concrete.

7. K. Ozawa, K. Maekawa, H. Okamura, Self-Compacting High-Performance Concrete. Collected Papers, University of Tokyo: Department of Civil Engineering, 1996, pp. 135-149.

8. M.U. Chandrakant, U.P. Pradnya, M.H. Shriram, K. Ravi, Comparative study of properties of self compacting concrete with metakaolin and cement kiln dust as mineral admixtures, Int. J. Res. Eng. Technol. 2 (4) (2014) 37-52.

\section{AUTHORS PROFILE}

Shijumon.V, is currently a Research Scholar.at Noorul Islam Centre for Higher, Kumaracoil, Kanyakumari District, Tamilnadu, INDIA

Dr. N. Nalanth is a Professor in the Department of Civil Engineering at Noorul Islam Centre for Higher, Kumaracoil, Kanyakumari District, Tamilnadu, INDIA. He has published over fifteen national and international journals and his research in focused on Self compacting concrete. 